\title{
Study of Seroprevalence and Associated Risk Factors of Contagious Bovine Pleuropneumonia in Sidama Zone, Southern Ethiopia
}

\author{
Gelgelo Malicha ${ }^{1}$, Sisay Alemu ${ }^{1 *}$, Fasil Aklilu ${ }^{2}$ and Ashebr Abraha ${ }^{1}$ \\ ${ }^{1}$ College of Veterinary Medicine, Haramaya University, P.O. Box 138, Dire Dawa, Ethiopia \\ ${ }^{2}$ National Animal Health Diagnostic \& Investigation Center (NAHDIC), P.O. Box 04, Sebeta, Ethiopia
}

*Corresponding author: Sisay Alemu, Haramaya University College of Veterinary Medicine, P.O. Box 138, Dire Dawa, Ethiopia, Tel: +251-25-5530334; E-mail: ssayalemu@gmail.com

Rec date: May 31, 2017; Acc date: September 18, 2017; Pub date: September 19, 2017

Copyright: (c) 2017 Malicha G, et al. This is an open-access article distributed under the terms of the Creative Commons Attribution License, which permits unrestricted use, distribution, and reproduction in any medium, provided the original author and source are credited.

\begin{abstract}
Contagious Bovine Pleuropneumonia (CBPP), a disease contributes significantly to cattle morbidity and mortality, remains the most important infectious disease of cattle in Ethiopia. Hence, a cross-sectional study was carried out in nine districts of Sidama Zone, to estimate animal level seroprevalence of CBPP in cattle, and to assess risk factors associated with its occurrence using competitive enzyme linked immunosorbent assay (c-ELISA). In the investigation, a total of 462 serum samples were collected and tested and the overall animal level sero-prevalence was recorded as $25.3 \%$. Among the host related potential predisposing factors assessed, age and body condition of the animals were not significantly $(p>0.05)$ associated with the occurrence of the disease, whereas sex of cattle was found significantly $(x 2=8.447, d f=2, p=0.004)$ associated. There was statistically significant $(x 2=21.2, d f=8, p=0.006)$ difference in the occurrence of CBPP among the nine districts of the Zone at individual animal level. Multi-variable logistic regression analysis showed that, males had 2.6 times $(\mathrm{OR}=2.6 ; \mathrm{Cl}=1.3-5.2)$ the odds of being negative for CBPP than female. Except sex of an animal, the other categorical variables were not significantly associated $(p>0.05)$ with occurrence of CBPP on univariable as well as multivariable logistic regression analysis. It is concluded that, CBPP is moderately prevalent in the study area. Therefore, it is needed to design and implement control measures directed at lowering and preventing further spread of the disease.
\end{abstract}

Keywords: CBPP; ELISA; Ethiopia; Risk factors; Sidama zone

\section{Introduction}

Contagious Bovine Pleuropneumonia (CBPP) is a disease of economic importance that is widely distributed in sub-Saharan African countries and contributes significantly to cattle morbidity and mortality. The disease is caused by Mycoplasma mycoides subsp. mycoides Small Colony ( $\mathrm{MmmSC}$ ), which is a highly contagious respiratory pathogen notifiable to the World Organization for Animal Health [1]. Its characteristic symptoms include anorexia, fever and respiratory signs, such as dyspnoea, polypnoea, cough and nasal discharge. While the disease is an immediate threat to livestock producers in the endemic regions of Africa, its implications in animal health is important in other geographical areas as well. Yearly losses directly or indirectly due to CBPP in Africa estimated to be around two billion US dollars [2]. Next to the eradication of rinderpest, CBPP is prime concern in African continent [3].

Contagious Bovine Pleuropneumonia remains the most important infectious disease of cattle in Ethiopia. It is one of the major threat in Ethiopia hindering and challenging the livestock production system [4-6]. In Ethiopia, various surveys have been carried out to estimate the prevalence of CBPP on livestock in different regions by various investigators. However, CBPP is not systematically studied in Sidama Zone and information is so far scanty on the overall status of the disease and possible risk factors associated with it. Therefore, the present study was aimed to estimate the sero-prevalence of CBPP among cattle in selected districts of Sidama Zone and to identify possible risk factors for the occurrence of the disease.

\section{Materials and Methods}

\section{Study area}

The study was carried out in selected nine districts (Bensa, Aroressa, Aleta Wondo, Hula, Aleta Chuko, Loko Abaya, Shebedino, Gorche and Melga) of Sidama Zone (Figure 1) from December 2015 to April 2016. Sidama zone covers approximately 6972 square kilometers and lies between 6.14-7.18 latitude and 37.92 to 39.19 longitudes, with an elevation ranging 501-3000 meters above sea level. The zone is divided in 19 Woredas. Regarding the agro-ecology of the zone, out of the total land size, $26.8 \%$ is Kolla, $45.49 \%$ Woinadega and $27.71 \%$ Dega. The annual mean temperature of the zone ranges between $10^{\circ} \mathrm{C}$ and $27^{\circ} \mathrm{C}$ and the annual mean rainfall ranges from $801 \mathrm{~mm}-1600 \mathrm{~mm}$. According to the land utilization data of the region, $50.67 \%$ is cultivated land, $17.57 \%$ grazing land, $6.51 \%$ forest bushes and shrub land, $17.84 \%$ cultivable, and the remaining $7.41 \%$ is covered by others. The livestock population of the zone is estimated as 2,131,224 cattle, 455,052 sheep, 267, 039 goats, 50,143 horse, 10, 008 mules and 69,941 donkey [7].

\section{Study design}

A field cross-sectional survey was carried out in selected districts of Sidama Zones of Southern Ethiopia to estimate the overall seroprevalence of CBPP by age, sex, location (altitude), breed and body condition scores. In each district, individual cattle were selected randomly after recording all the animals in the herd. The altitude of districts was categorized in to two based on the elevation of the sites. In that those with elevation of 1500-2500 meter above sea level were 
categorized as Weina dega while Dega was assigned for 2500-3000 masl.

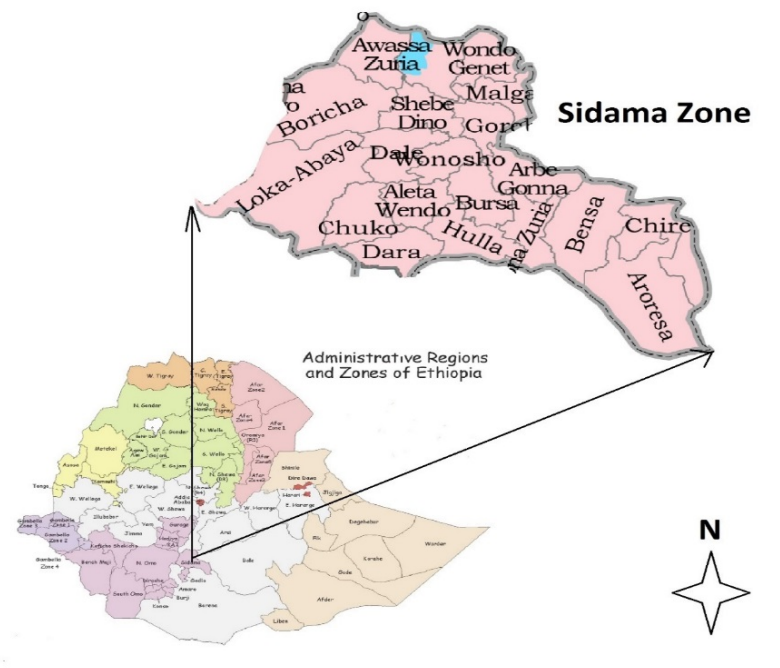

Figure 1: Map showing the location of the study area.

\section{Study animals}

For the serological study, cattle above the age of six months with no history of vaccinations to CBPP were included. Study animals related information on each tested cattle (such as sex, age, body condition score, breed and location) were recorded at the time of sample collection. The cattle in this study area were mainly local breeds which are categorized under Sanga breed group. The ages and body condition scores were scored according to De Lahunta and Habel [8] and Nicholson and Betterworth [9], respectively. Accordingly, by observing the sites such as ribs, vertebral column, spines animals were categorized as poor ( 1 and 2 ) moderate ( 3 and 4$)$ and good (>5). Age were categorized as young ( $<3$ years old) and adult ( 3 years and above) based on the categorization made by previous experimental studies [10]. Sample size was determined according to Thrusfield [11] considering the recommendation for sample size estimation based on $50 \%$ expected prevalence. Based on this estimation, the estimated sample size was 384 . However, to increase precision the sample size was increased to 462 .

Sampling strategy: Multistage sampling was used according to the following:

Primary sampling unit: Kebeles/Peasant Associations/PA's as the smallest administrative unit were used as primary sampling unit. Within each selected District, PA/PA's were selected randomly from the district PAs list randomly. From 9 selected Weredas a total of 11 PA's one PA from 7 Weredas and from other two Weredas two Kebeles from each Wereda were selected.

Secondary sampling unit: Villages/herds were taken as secondary sampling unit. From each PA only three Villages were selected randomly for sampling based on the availability of cattle population.

Tertiary sampling unit: Individual cattle were taken as tertiary sampling unit. From each village/herd about 14-16 individual cattle not vaccinated against CBPP and above 6 months of age found in a household herds/village were randomly selected and sampled for the seroprevalence study.

The sampling design was as follows: The Zone is purposively selected from the region; Under the Zone Weredas were selected randomly from the Wereda list and under the Wereda Kebeles were selected randomly from the Kebele list. In most of the selected Weredas only one Kebele was included for sample collection but from two Weredas (Bensa and Malga) two Kebeles were randomly selected for sample collection. In each district sample size was determined based on cattle population and size of the wereda. To reach the recommended sample size we randomly selected 3 villages/herds from one Kebele and from each herd/village about 14-16 animals were included for sample collection.

\section{Sample collection and analysis}

Animals were restrained by owners and 5-10 $\mathrm{ml}$ of blood sample was collected from the jugular vein using vacationer tubes under aseptic condition. The samples were kept under the shade in a slant position for twenty-four hours. The sera samples were transferred to serum tubes (cryovial tube) and kept at $-20^{\circ} \mathrm{C}$ until tested. Then serum samples were analysed using competitive ELISA (cELISA) for the detection of contagious bovine pleuropneumonia antibodies according to OIE standard [12] at National animal health diagnostic and investigation center (NAHDIC) bacterial serology laboratory.

\section{Competitive ELISA (c-ELISA) procedures}

The wells of the polystyrene micro-plate were coated with an MmmSC purified lysate. Test Serum samples were premixed with a specific monoclonal antibody Mab 117/5 in a pre-plate. This mixture was then transferred into the MmmSC antigen coated micro-plate. Any antibody specific to MmmSC in the serum forms an immunecomplex with MmmSC antigen coated on the microplate, competing with Mab 117/5 for the specific epitopes. After washing away unbound material, an anti-mouse antibody enzyme conjugate was added. In presence of immune-complex between MmmSC antigen and antibody from the sample, Mab 117/5 cannot bind to its specific epitopes and the conjugate is blocked from binding to Mab 117/5. Conversely in the absence of MmmSC antibodies in the test sample, Mab 117/5 can bind to its specific epitopes and the conjugate is free to bind to Mab 117/5. After washing unbound conjugate away, enzyme substrate (TMB) was added. In the presence of the enzyme, the substrate is oxidized and develops a blue compound becoming yellow after blocking. Subsequent color development is inversely proportional to the amount of antMmmSC Antibodies in the test sample. The result was expressed in "percentage of inhibition "by comparing the optical density in the test well with the optical densities in the mab control wells [12].

\section{Data management and analysis}

Data were classified, filtered, coded using Microsoft Excel sheet, and was transferred and analyzed using SPSS version 20. Pearson chiSquare was used to evaluate the statistical significance of the associations of different categorical variables with seroprevalence of CBPP. Univariable and multivariable logistic regression analyses were performed to quantify crude and adjusted effects of pre-specified risk factors on CBPP seroreactivity. P-value less than 5\% was considered statistically significant. 
Citation: Malicha G, Alemu S, Aklilu F, Abraha A (2017) Study of Seroprevalence and Associated Risk Factors of Contagious Bovine

Page 3 of 5

\section{Results}

\section{Overall prevalence of Contagious Bovine Pleuropneumonia (CBPP)}

In the present study, a total of 462 cattle were examined and the overall sero-prevalence of CBPP was $25.3 \%$. The highest CBPP seroprevalence (38.1\%) was recorded in Gorche district while the lowest sero-prevalence $(7.1 \%)$ was recorded in Shebedino district. Meanwhile, statistically significant variation was recorded among the studied districts $(\mathrm{p}=0.006)$ (Table 1$)$.

\begin{tabular}{|l|l|l|l|l|l|}
\hline Districts & $\begin{array}{l}\text { Number of } \\
\text { tested } \\
\text { Animals }\end{array}$ & $\begin{array}{l}\text { Number of } \\
\text { positive }\end{array}$ & $\begin{array}{l}\% \\
\text { positive }\end{array}$ & $\mathbf{X}^{2}$ & p-value \\
\hline Bensa & 83 & 30 & 36.1 & & \\
\hline Aroressa & 43 & 11 & 25.6 & & \\
\hline Aleta Wondo & 42 & 14 & 33.3 & & \\
\hline Hula & 42 & 6 & 14.3 & & \\
\hline Aleta Chuko & 42 & 9 & 21.4 & 21.3 & 0.006 \\
\hline Loko Abaya & 42 & 10 & 23.8 & & \\
\hline Shebedino & 42 & 3 & 7.1 & & \\
\hline Gorche & 42 & 16 & 38.1 & & \\
\hline Melga & 84 & 18 & 21.4 & & \\
\hline Total & 462 & 117 & 25.3 & & \\
\hline
\end{tabular}

Table 1: Individual animal level sero-prevalence of contagious bovine pleuropneumonia in selected districts of Sidama Zone, Southern Ethiopia.

\section{Association of risk factors with the occurrence of CBPP}

Host and environment related potential risk factors like sex, age, breed, location and body condition of the animals were associated with CBPP sero-status of the animals. However, only sex of an animal showed statistically significantly difference $(p<0.05)$ in seroprevalence of CBPP. Due to unbalanced sample size, statistical analysis of CBPP association with breed was not performed (Table 2).

\begin{tabular}{|c|c|c|c|c|}
\hline Variables & $\begin{array}{l}\text { Number of } \\
\text { cattle } \\
\text { examined }\end{array}$ & $\begin{array}{l}\text { Number of } \\
\text { positive (\%) }\end{array}$ & $x^{2}$ & $p$-value \\
\hline \multicolumn{5}{|l|}{ Sex } \\
\hline Female & 377 & $106(28.1)$ & \multirow[t]{2}{*}{8.4} & \multirow[t]{2}{*}{0.004} \\
\hline Male & 85 & $11(12.9)$ & & \\
\hline \multicolumn{5}{|l|}{ Age } \\
\hline Adult & 177 & $46(26)$ & \multirow[t]{2}{*}{0.1} & \multirow[t]{2}{*}{0.8} \\
\hline Young & 285 & 71 (24.9) & & \\
\hline \multicolumn{5}{|l|}{ Breed } \\
\hline Local & 459 & $115(25.1)$ & & \\
\hline Cross & 3 & $2(66.7)$ & & \\
\hline \multicolumn{5}{|l|}{ BCS } \\
\hline Poor & 56 & $18(32.1)$ & & \\
\hline Moderate & 169 & $46(27.2)$ & 2.8 & 0.2 \\
\hline Good & 237 & $53(22.4)$ & & \\
\hline \multicolumn{5}{|l|}{ Altitude } \\
\hline Dega & 168 & $40(23.8)$ & \multirow[t]{2}{*}{0.3} & \multirow[t]{2}{*}{0.6} \\
\hline Woinadega & 294 & 77 (26.2) & & \\
\hline
\end{tabular}

Table 2: Association of different risk factors to CBPP seropositivity.

In univariable logistic regression analysis, male had 2.6 times the odds of being negative for CBPP than female $(\mathrm{OR}=2.6$; $\mathrm{CI}=1.3-5.2)$ on serological examination. Similarly, animals in good body score had 1.6 times of being negative for CBPP $(\mathrm{OR}=1.6$; $\mathrm{CI}=0.9-3.1)$. Both in univariable and multivariable analysis, sex remained significantly $(p<0.05)$ associated with seropositivity. However, the other factors remained statistically insignificant ( $>0.05)$ (Table 3 ).

\begin{tabular}{|c|c|c|c|c|c|}
\hline \multirow{3}{*}{ Variable } & \multirow{3}{*}{$\%$ of CBPP prevalence } & \multicolumn{2}{|c|}{ Univariable logistic regression } & \multicolumn{2}{|c|}{ Multivariable logistic regression } \\
\hline & & Crude odds ratio & $x^{2}$ & Adjusted odds ratio & $\mathbf{x}^{2}$ \\
\hline & & $(95 \% \mathrm{Cl})$ & (p-value) & $(95 \% \mathrm{Cl})$ & (p-value) \\
\hline \multicolumn{6}{|l|}{ Sex } \\
\hline Female & 28.1 & 1 & \multirow{2}{*}{$9.5(0.002)$} & 1 & \multirow{2}{*}{$7.3(0.007)$} \\
\hline Male & 12.9 & $2.6(1.3-5.2)$ & & $2.6(1.3-5.2)$ & \\
\hline \multicolumn{6}{|l|}{ Age } \\
\hline Adult & 26 & 1 & \multirow{2}{*}{$0.1(0.8)$} & 1 & \multirow{2}{*}{$1.3(0.2)$} \\
\hline Young & 24.9 & $1.1(0.7-1.6)$ & & $0.7(0.5-1.2)$ & \\
\hline \multicolumn{6}{|l|}{ Altitude } \\
\hline Dega & 23.8 & 1 & $0.3(0.6)$ & 1 & $0.5(0.5)$ \\
\hline
\end{tabular}


Page 4 of 5

\begin{tabular}{|l|l|l|l|l|l|}
\hline woinageda & 26.2 & $0.9(0.6-1.4)$ & & $0.8(0.5-1.4)$ & \\
\hline BCS & & & & & \\
\cline { 1 - 2 } Poor & 32.1 & 1 & \multirow{2}{*}{$2.8(0.2)$} & 1 & $2.6(0.3)$ \\
\cline { 1 - 3 } Moderate & 27.2 & $1.3(0.7-2.4)$ & $1.8(0.9-3.6)$ & \\
\cline { 1 - 3 } Good & 22.4 & $1.6(0.9-3.1)$ & & $1.4(0.7-2.7)$ & \\
\hline
\end{tabular}

Table 3: Logistic regression analysis of seroreactivity in relation with host and environment related risk factors.

\section{Discussion}

In the present study, a moderately high prevalence rate $(25.3 \%)$ of CBPP was reported in studied districts of Sidama Zone, Southern Ethiopia. The highest was reported in Gorche district (38.1) while the lowest was reported in Shebedino district (7.1\%), indicating a variation within the zone. The higher prevalence reported in Gorche could be related to large number of animals reared by an individual farmer and large grazing land existing in the district which allows animals to contact with an infected animal from outbreak area. There was statistically significant difference $(p<0.05)$ in the occurrence of the disease based on districts. This finding is similar with that of Daniel, et al. [13], who reported statistically significant variation $(\mathrm{p}<0.05)$ in seroprevalence between districts.

The overall prevalence obtained, in general, was lower than the previous reports from other area of Ethiopia. Thus, from Bodji district of Western Wellega, Western Ethiopia, Somali regional state and North Omo, a $28 \%, 32.5 \%, 39 \%$ and $56 \%$ prevalences were reported by Ragassa [14], Desta [15], Gedlu [4] and Dejene [16], respectively. On the other hand, the result of the present study was much higher than the findings of Ahmed [17], Gashaw [18], Matua-Alumira et al. [19], Kassaye and Molla [20] and Teshale, et al. [21] who reported seroprevalence of 9.4\% (in Borena), 9.1\% (in northwest Ethiopia), 16\% (in Kajiado district Kenya), 4\% (in and around Adama) and $11.9 \%$ (in southern zone of Tigray region), respectively. The variation in the prevalence of CBPP reported from different part of Ethiopia could be due to difference in agro-ecology, management, production system, population density, the types of tests used to evaluate the seroprevalence.

In the present study, statistically significant association $(\mathrm{p}=0.002)$ was observed in seropositivity among sex categories in that females were more sero reactive. Meanwhile, multivariable logistic regression showed that sex was significantly associated with seroposisitivity. This result was similar with Schnier [22], who reported significantly higher prevalence in female as compared to male animals in Kenya. This finding does not concur with that of [13], who reported insignificantly higher prevalence in male animals in Ethiopia.

The sero-prevalence of CBPP has showed an increase with age. In addition, higher prevalence was reported with reduced body condition and altitude. However, there was no statistically significant variation $(p>0.05)$ among age, body condition and altitude category. In line with the present finding, Biruhtesfa et al. [23] reported that animals with poor body condition had higher seropositivity as compared to the moderate and good body conditions. Moreover, this result agreed with previous report by Teshale et al. [21] in which they reported insignificant $(p>0.05)$ difference of seroprevalence among age groups. In line with the present finding Daniel et al. [13] and Mersha [24] reported that there was no statistically significant difference $(\mathrm{p}>0.05)$ in prevalence among age and body condition categories. The agerelated similarity in prevalence could be due to similar exposure of animals to the disease since the disease is contagious that all animal in the herd can be affected and a single diseased animal can serve as continuous source of infection to the herd. Furthermore, the disease is mainly transmitted from animal to animal in aerosols and the organism is usually found in saliva, urine, fetal membranes and uterine discharges. Hence, there could be uniformity of infection in all age groups [25]. Over all the relatively higher prevalence in adult as compared to young animals is supported by the finding of Emanuel [26] and Matua-Alumira et al. [19], who reported relatively higher serorevalence in adults as compared to the young. However, in experimental study cattle greater than 3 years old were more resistance than younger animals [10]. But no attempt was made to give explanation for this age-related susceptibility. Low prevalence of infection in young could be due to the decreased contact between the other animals because young animals don't move long distance while grazing in the field. Moreover, it is well understood that c-ELISA is more sensitive in detecting cattle with chronic stage than any other test, and it is more prone to miss individual animals at the early stage of infection $[27,28]$.

\section{Conclusions}

In conclusion, CBPP was found to be moderately prevalent (25.3\%) in the study area with some degree of variation among districts. The presence of statistically significant variation in seroprevalence of CBPP among the districts and sex indicates that there could be some management related factors favoring the occurrence of disease. Hence, there is a need to develop scheme and implement control measures directing at preventing further spread and lowering the prevalence of the disease in the zone through the use of better and coordinated therapeutic and vaccination program.

\section{Conflict of Interests}

The authors declare that there is no conflict of interests regarding the publication of this paper.

\section{Acknowledgements}

The authors are thankful to National Animal Health Diagnostic and Investigation Center (NAHDIC) and Haramaya University for facilitation and assistance of this research work. We are also grateful to laboratory and field personnel's of the NAHDIC, Sebeta, Ethiopia for their continuous encouragement, guidance and kind correspondence up to completion of this work. 
Citation: Malicha G, Alemu S, Aklilu F, Abraha A (2017) Study of Seroprevalence and Associated Risk Factors of Contagious Bovine Pleuropneumonia in Sidama Zone, Southern Ethiopia. J Vet Sci Technol 8: 471. doi:10.4172/2157-7579.1000471

Page 5 of 5

\section{References}

1. OIE, Terrestrial Animal Health Code: General Disease Information Sheets.

2. FAO-OIE, Food and Agricultural Organization-Organization of International des Epizooties (2003) Consultative Group on CBPP, 12-14 November, Rome, Italy: Towards sustainable CBPP control programmes for Africa.

3. Amanfu W, Sediale S, Masapu KV, Benkirane A, Geiger R, et al. (1998) Field validation of a competitive enzyme-linked immunosorbent assay for the detection of contagious bovine pleuropneumonia in Botswana. J Livest Vet Med Tropical Countries 51: 189-193.

4. Gedlu MG (2004) Serological, Clinical and Participatory epidemiological survey of CBPP in Somali Region. MSc Thesis, Addis Ababa University, Debre Zeyit Ethiopia, p: 75.

5. Dele E, Afera B, Kebede E, Awol N, Hadush B (2014) Sero prevalence of Trade Hampering Livestock Diseases in Animals Originated from Borena at Export Quarantine Centers in Adama, Central Ethiopia. African J Basic Appl Sci 6: 30-36.

6. Alemayehu G, Leta S, Hailu B (2014) Sero-prevalence of Contagious Bovine Pleuropneumonia (CBPP) in bulls originated from Borena Pastoral Area of Southern Ethiopia. Anim Vet Sci 2: 213-217.

7. CSA (2014/15) Agricultural sample survey, Statistical bulletin 578, Addis Ababa, Ethiopia.

8. De-Lahunta A, Habel RE (1986) Applied veterinary Anatomy. USA. WB Sounders Company. pp: 4-16.

9. Nicholson MJ, Butterworth $\mathrm{MH}$ (1986) A guide to condition scoring of zebu cattle. International Livestock Centre for Africa, Addis Ababa, Ethiopia. p: 29.

10. Masiga WN, Windsor RS (1978) Some evidence of an age susceptibility to contagious bovine pleuropneumonia. Res Vet Sci 24: 328-333.

11. Thrusfield M (2005) Veterinary epidemiology. 3rd edn. Black well, pp: 384-386.

12. OIE (2014) OIE terrestrial manual.

13. Daniel G, Abdurahaman M, Tuli G, Deresa B (2016) Contagious bovine pleuropneumonia: Seroprevalence and risk factors in Western Oromia, Ethiopia. Onderstepoort J Vet Res 83: 958.

14. Regassa F (2001) Herd prevalence of Contagious Bovine Pleuropneumonia (CBPP), Bovine Tuberculosis and Dictyocaulosis in Bodji woreda, west Wellega, DVM Thesis, Faculty of Veterinary Medicine, Addis Ababa University, Debre Zeyit, Ethiopia.

15. Desta B (1998) Sero-epidemiological Investigation of CBPP in Ilu Ababor and Wellega. DVM Thesis, FVM, AAU, Western Ethiopia, p: 48.

16. Dejene W (1996) Contagious Bovine Pleuropneumonia (CBPP): Prevalence and Evaluation of Post-Vaccination immune response (North Omo, Konso and Dirashe Regions/Ethiopia). DVM Thesis, Faculty of Veterinary Medicine, Addis Ababa University, Debre Zeyit, Ethiopia, pp: 37-48.
17. Ahmed I (2004) Epidemiological study of contagious bovine pleuropneumonia in Borena pastoral areas using Complement Fixation Test and Competitive Enzyme-Linked Immunosorbent Assay. Un published MSc Thesis, Addis Ababa University.

18. Gashaw T (1998) Epidemiological survey of CBPP in Awi and Western Gojjam zone of Amhara Region and comparison of CFT and C-ELISA for the diagnosis of CBPP. Un published MSc Thesis, Addis Ababa University and Freie Universität, Debre Zeyit, Ethiopia, p: 5.

19. Matua-Alumira RW, Ng'ang'a Z, Kiara H, Matere C, Mbithi F, et al. (2006) The prevalence of Contagious Bovine Pleuropneumonia (CBPP) in cattle under different production systems in Kajiado district, Kenya. Proceedings of the 11th Symposium on Veterinary, Kenya.

20. Kassaye D, Molla W (2013) Seroprevalence of contagious bovine pleuropneumonia at export quarantine centers in and around Adama, Ethiopia. Trop Anim Health Prod 45: 275-279.

21. Teshale T, Temesgen T, Tsigabu N, Birhanu H, Solomon W, et al. (2015) Epidemiological Status of Contagious Bovine Pleuropneumonia in Southern Zone of Tigray Regions, Northern Ethiopia. Anim Vet Sci 3: 32-36.

22. Schnier C, Mtui-Malamsha NJ, Cleaveland S, Kiara H, Grace D, et al. (2006) CBPP Seroprevalence and Associated Risk Factors in the Maasai Ecosystem of South-western Kenya. Moredun Research Institute, Penicuik, UK.

23. Biruhtesfa A, Henok G, Hundera S, Surafel K (2015) Sero-Prevalence of Contagious Bovine Pleuropneumonia in Abattoirs at Bishoftu and Export Oriented Feedlots around Adama. Global Veterinaria 15: 321-324.

24. Mersha T (2016) Sero-prevalence of contagious bovine pleuropneumonia and its potential risk factors in selected sites of Western Oromia, Ethiopia. Ethiopian Vet J 20: 31-34.

25. Radiostits OM, Gay CC, Hinchcliff KW, Constable PD (2008) Veterinary medicine a textbook of the disease of cattle, sheep, pigs, Goats and horses. 10th edn. Saunders Elsevier's.

26. Emanuel S, Isidory M, Edward U, Adam M, Winford M (2013) An abattoir survey of contagious bovine pleuropneumonia lesions in slaughtered cattle in selected districts in Northern Tanzania. Asian Pac J Trop Biomed 3: 303-306.

27. Muuka G, Hang'ombe BM, Nalubamba KS, Kabilika S, Mwambazi L, et al. (2011) Comparison of Complement Fixation Test, Competitive ELISA and Lpp Q ELISA with Post-mortem Findings in the Diagnosis of Contagious Bovine Pleuropneumonia (CBPP). Trop Anim Health Prod 43: 1057-1062.

28. Schubert E, Sachse K, Jores J, Heller M (2011) Serological testing of cattle experimentally infected with Mycoplasma mycoides subsp. mycoides small colony using four different tests reveals a variety of sero-conversion patterns. BMC Vet Res 7: 72. 